\title{
Uma proposta para a inclusão de tópicos de astronomia indígena brasileira nas aulas de Física do Ensino Médio
}

\author{
A proposal for inclusion of topics from the Brazilian \\ indigenous astronomy for high school Physics classes
}

\author{
Diones Charles Costa de Araújo ${ }^{1}$. Maria de Fátima da Silva Verdeaux ${ }^{2}$.
}

Walmir Thomazi Cardoso ${ }^{3}$

\begin{abstract}
Resumo: Neste artigo são apresentados os resultados obtidos durante a aplicação de uma experiência didática que inseriu tópicos de Astronomia Indígena Brasileira (AIB) nas aulas de Física do Ensino Médio (EM). O trabalho de pesquisa teve como suporte teórico os conceitos da Etnoastronomia e referências inspiradas na pedagogia dialógica de Paulo Freire com intuito de estudar o Céu noturno com o olhar voltado para diferentes Culturas indígenas. A proposta apresentada foi desenvolvida em uma escola da rede particular de ensino de Taguatinga, Distrito Federal, Brasil, sendo realizada por meio de aulas expositivas e práticas direcionadas aos estudantes do $1^{\circ}$ ano do EM. Considerando a falta de materiais publicados e disponíveis sobre o tema, produziu-se um material didático instrucional com a finalidade de contribuir com a prática docente. $\mathrm{O}$ texto disponível nesse recurso serviu de apoio reflexivo e as sugestões de atividades, como práticas educacionais, permitiram a efetividade da proposta.
\end{abstract}

Palavras-chave: Ensino de Astronomia. Etnoastronomia. Astronomia indígena brasileira.

\begin{abstract}
This article presents the results obtained during the application of a didactic experience that inserted topics of Brazilian Indigenous Astronomy (AIB) in High School Physics classes. The research work had as theoretical support the concepts of Ethnoastronomy and references inspired in dialogical pedagogy of Paulo Freire in order to study the night sky with the look toward to different indigenous cultures. The proposal presented was developed in a private school in Taguatinga, Federal District, Brazil, being carried out through lectures and practices directed to 1st year of High School. Considering the lack published and available material on the subject an instructional didactic material was produced with the purpose of contributing to the teaching practice. The text available in this resource served as a reflective support and suggestions for activities such as, educational practices, thus enabling the effectiveness of the proposal.
\end{abstract}

Keywords: Astronomy teaching. Ethnoastronomy. Brazilian indigenous astronomy.

\footnotetext{
${ }^{1}$ Universidade de Brasília (UnB), Programa de Pós-Graduação em Ensino de Ciências, Brasília, DF, Brasil. E-mail: $<$ diones.araujo@catolica.edu.br>.

${ }^{2}$ Universidade de Brasília (UnB), Instituto de Física, Brasília, DF, Brasil.

${ }^{3}$ Pontifícia Universidade Católica de São Paulo (PUCSP), Departamento de Física, São Paulo, SP, Brasil.
} 


\section{Introdução}

A Astronomia é considerada um dos campos mais antigos do conhecimento humano "[...] sendo difícil identifcar uma Cultura que não tenha se ocupado em observar cuidadosamente o Céu” (CARVALHO FILHO; GERMANO, 2007, p. 2). Cada povo vê e o interpreta de formas bem diversificadas segundo contextos, padrões de comportamento, crenças, conhecimentos, costumes e valores que se alteram em espaços e tempos diferentes.

Nessa perspectiva, com Astronomia ${ }^{4}$ própria e caracterizada por padrões diferentes daqueles praticados pelo campo acadêmico de investigações da Cultura Ocidental, os índios brasileiros também estabelecem a contagem de tempo, realizam suas atividades rotineiras de coleta, caça e pesca assim como representam no Céu noturno parte de seus mitos, além de evidenciarem por meio dessas práticas a complexidade de seus rituais e das relações naturais, espirituais e socioambientais típicas de suas Culturas.

No campo educacional a Astronomia faz parte do programa curricular do ensino básico brasileiro. Os Parâmetros Curriculares Nacionais para o Ensino Médio ( $\mathrm{PCN}+$ ) indicam o estudo dessa ciência na área de Física na perspectiva do eixo Universo, Terra e Vida. Já a proposta curricular para o Ensino Médio sugere estudos dentro de três unidades temáticas: "Terra e Sistema Solar", "O Universo e sua origem" e "Compreensão humana do Universo".

Tomando como referência esses documentos oficiais pode-se, portanto, afirmar que o ensino da Astronomia em suas diversas modalidades é estimulado e esperado na etapa de formação básica dos estudantes. Além disso, trata-se de uma temática que desperta o interesse dos estudantes pelas imagens impressionantes do Universo que vemos diariamente na Internet, assim como por outros assuntos diversificados ligados a Ciências Básicas e Aplicadas. Para Caniatto (1990 apud LINHARES; NASCIMENTO, 2009, p. 2), muitas razões justificam a importância dada a esse ensino: “[...] ela é a mais antiga das ciências, nenhum outro conhecimento tem estado desde a antiguidade tão ligada ao desenvolvimento do pensamento humano, além de possuir o conteúdo altamente motivador exercendo um grande fascínio".

Embora a importância de ensinar Astronomia na Educação Básica seja reconhecida e estimulada através de vários mecanismos as dificuldades para torná-la realidade na educação formal são perceptíveis e alvo de estudos acadêmicos a esse respeito. A tentativa de inserir o que denominamos de Astronomia Indígena Brasileira (AIB) ${ }^{5}$ nas aulas de Física do Ensino Médio se

\footnotetext{
4 "Um considerável número de profissionais em Astronomia discute a adequação do uso desse termo para designar a prática realizada pelos povos indígenas, quilombolas, pequenos produtores rurais envolvendo estrelas, planetas, Sol e Lua dentre outros astros e manifestações gerais que ocorrem no Céu" (e.g., JAFELICE, 2012, 2016; LIMA et al., 2014). Apesar de ser uma área visivelmente ligada à Antropologia, mundialmente a expressão "Astronomia Cultural" tem sido empregada para designar essas práticas e por isso mesmo estamos utilizando a palavra "Astronomia" no sentido de se utilizar toda e qualquer manifestação envolvendo o Céu e as Culturas, neste artigo.

${ }^{5}$ Astronomia Indígena Brasileira (AIB) é compreendida nesse trabalho como o conjunto ou parte do conjunto de interpretações de fenômenos associados ao Céu, pelas diversificadas etnias indígenas brasileiras. Valem inclusive fenômenos que reconhecemos como meteorológicos, que estão ou não ligados a objetos celestes que penetram na atmosfera, como é o caso dos meteoritos, por exemplo.
} 
Uma proposta para a inclusão de tópicos de astronomia indígena brasileira ...

torna um desafio maior ainda, até mesmo por ser um assunto pouco explorado e divulgado no meio acadêmico universitário e nas escolas. De fato, o ensino da Astronomia Cultural (AC) na sala de aula é raro, porém, julgamos que para aplicação de uma proposta como essa é necessário uma abordagem que venha desenvolver: o domínio dos conteúdos por parte dos professores, a organização do conhecimento de maneira contextualizada e a utilização de representações e situações reais presentes no cotidiano dos estudantes.

Portanto, para que uma proposta dessa natureza se torne eficaz é preciso, também, considerar a formação dos professores, especificamente na área de Ciências e Física, e seu interesse pela pesquisa a fim de adquirirem noções básicas de Astronomia, assim como de Etnoastronomia ${ }^{6}$ e de Arqueoastronomia ${ }^{7}$ para complementar e desenvolverem os seus trabalhos com eficiência durante a aplicação desses temas. Segundo Jafelice (2013, p. 3):

[...] a pesquisa em AC exige formação disciplinar diversificada, disposição para um diálogo interdisciplinar, com espírito transdisciplinar, incorporação da concepção de mundo holística, adoção de uma perspectiva relativista na compreensão e tradução da visão de mundo do outro e postura de acolhimento autêntico da diversidade cultural, em especial o da diversidade epistemológica nas construções de significados das outras culturas.

Por outro lado considerando a escola um ambiente formal de aprendizagem a abordagem de novos conteúdos estão diretamente relacionadas aos assuntos apresentados no programa da disciplina (conteúdo programático), desde a sua relação com o cotidiano até os conteúdos presentes nos livros didáticos. É certo que para os professores que optarem por incluir em seu plano de aula a AC, o domínio e o interesse em aprender novas temáticas possibilitará a eles uma maior autonomia o que facilitará a inserção de novos temas propostos.

Nesse aspecto o desafio de inserir AIB nas aulas de Física não é uma tarefa fácil e por isso alguns questionamentos surgiram durante a formulação da pesquisa:

- Qual a justificativa para a inserção da AIB no Ensino Médio?

- Será a AIB apenas mais um tópico do Ensino de Astronomia?

- Existem livros didáticos de Física do Ensino Médio que inserem temas de AIB?

- Existem materiais de apoio didático disponíveis para o professor sobre AIB?

Para responder essas questões seria importante encontrar outras tentativas de inserção desse tipo de conhecimento nas práticas escolares ou ainda o que há de Astronomia Cultural disponível nas pesquisas para ser ensinada na Educação Básica.

\footnotetext{
6 "A Etnoastronomia é a ciência que tem por fim estudar, por intermédio dos costumes de um povo, os seus conhecimentos astronômicos" (MOURÃO, 1987, p. 289).

7 “Ciência que tem por objetivo estudar os conhecimentos astronômicos dos povos antigos, em especial os do período pré-histórico; astronomia arqueológica, arqueologia astronômica, astroarqueologia” (MOURÃO, 1987, p. 59).
} 


\section{Revisão de trabalhos publicados sobre o Ensino de Astronomia e Astronomia Cultural}

Com objetivo de buscar informações que pudessem complementar a essência deste trabalho, realizou-se uma revisão de literatura no âmbito das pesquisas desenvolvidas na área do Ensino de Astronomia publicadas em artigos disponíveis em revistas eletrônicas de Ensino de Física, Ciências e Astronomia. Procurou-se direcionar a pesquisa em três linhas de investigação: Ensino de Astronomia, Material Didático na área de Astronomia e Etnoastronomia. Houve dificuldade em obter informações sobre Etnoastronomia indígena brasileira nos periódicos consultados devido à carência de publicações e por esse motivo foram incluídos artigos apresentados em eventos que trataram do tema, além de dissertações e teses. Buscou-se também analisar livros didáticos de Física do Ensino Médio a fim de verificar se esses materiais abordam alguns tópicos de Astronomia.

Dos periódicos consultados entre os anos de 2002 a 2016 obteve-se 198 artigos que tratam especificamente sobre Ensino de Astronomia. As publicações em sua maioria abordam relatos de experiências vividas em um ambiente formal de ensino, contextos históricos ou direcionados ao estudo de alguns astros (Sol, Lua, planetas, etc.). Quanto à produção de materiais didáticos instrucionais na área de Astronomia notou-se pouco destaque em relação aos artigos que tratam sobre o Ensino de Astronomia e/ou Ensino de Física. Do total de artigos consultados apenas três são direcionados ao estudo da Astronomia Cultural no qual um faz uma pequena abordagem sobre Etnoastronomia indígena brasileira (FARES et al., 2004) e dois apresentam propostas didáticas para o ensino da AIB (JAFELICE, 2015; GARCIA et al., 2016). Da revisão de literatura realizada no âmbito da Astronomia Cultural (AC) a análise foi efetuada em artigos específicos, dissertações e teses que tratam da Etnoastronomia dos povos indígenas brasileiros.

O artigo de Faulhaber (2004) trata sobre a Antropologia do clima que abrange o estudo da significação dos fenômenos astronômicos e atmosféricos nos mitos e ritos indígenas, bem como a importância das representações sobre tais fenômenos para as práticas sociais de povos indígenas como o Ticuna ${ }^{8}$. A autora aborda

[...] a identificação dos corpos celestes, presentes na iconografia dos artefatos utilizados na festa de puberdade Ticuna que remete a aspectos da mitologia e da cosmovisão deste povo, expressos em cantos e relatos de rituais, traduzidos em termos das expectativas em face das relações entre o movimento das estrelas no Céu ao longo do ano e a influência da sazona-

\footnotetext{
8 “Os Ticuna configuram o mais numeroso povo indígena na Amazônia brasileira. A língua Ticuna é amplamente falada em uma área extensa por numerosos falantes (acima de 30.000) cujas comunidades se distribuem por três países: Brasil, Peru e Colômbia. No lado brasileiro, o número de comunidades ascende a um alto número de aldeias (cerca de 100) contidas em diversas áreas localizadas em vários municípios do estado do Amazonas (entre os quais estão Benjamin Constant, Tabatinga, São Paulo de Olivença, Amaturá, Santo Antonio do Içá, Jutaí, Fonte Boa, Tonantins, Beruri). A maior parte das aldeias encontra-se ao longo e nas proximidades do rio Solimões” (INSTITUTO SOCIOAMBIENTAL, 2008).
} 
Uma proposta para a inclusão de tópicos de astronomia indígena brasileira ...

lidade das chuvas e da estiagem nas atividades de sobrevivência". [...] Tal identificação de agrupamentos de corpos celestes visualizados pelos Ticuna permite correlações com as constelações reconhecidas convencionalmente. (FAULHABER, 2004, p. 1).

Lima (2004a) aborda em sua pesquisa as observações e descrições astronômicas de indígenas brasileiros tendo como embasamento a visão dos missionários, colonizadores, viajantes e naturalistas. A pesquisadora analisou alguns dos mais importantes documentos históricos que trazem informação sobre a Etnoastronomia de povos indígenas. Segundo a autora, o seu “[...] trabalho teve como objetivo construir um quadro geral dos conhecimentos astronômicos indígenas como descritos e interpretados por europeus e pesquisadores brasileiros, portanto, sendo um trabalho com forte filiação metodológica na História da Ciência” (LIMA, 2004b, p. 175).

Barros (2004) utilizou a Cultura dos índios Tembé-Tenetehara9 como matriz Etnomatemática ${ }^{10}$ no Ensino Fundamental para fazer uma leitura do Céu juntamente com seus elementos astronômicos como matriz de explicação da Astronomia científica. Propõe a partir de uma interface com a Matemática escolar, estratégias de aproximação dos conteúdos escolares dessa disciplina tendo em vista a articulação dialogal entre saberes no contexto da Sociedade e da Cultura e os saberes científicos disseminados pela Escola.

Lima e Moreira (2005) abordam sobre as tradições astronômicas tupinambás na visão de Claude D’Abbeville. Os pesquisadores apresentam uma análise de um dos mais importantes documentos históricos brasileiros sobre conhecimentos astronômicos indígenas: Histoire de la mission des Pères capucins en l'isle de Maragnan et terres ciconvoisines, où est traicté des singularitez admirables et des meurs merveilleuses des Indiens habitans de ce pais, de Claude D'Abbeville (1557-1632), publicado em 1614 (LIMA; MOREIRA, 2005). Segundo os autores “[...] a crônica traz descrições de constelações, sistemas de calendário e alguns conhecimentos astronômicos empíricos" (LIMA; MOREIRA, 2005, p. 1). O livro traz conhecimentos e saberes relacionando a Astronomia e outros temas desenvolvidos pelos tupinambás do Maranhão, descritos e interpretados por esse missionário francês. "As informações históricas são também cotejadas com estudos etnográficos recentes sobre grupos indígenas atuais" (LIMA; MOREIRA, 2005, p. 1).

Cardoso (2007) apresenta um estudo minucioso realizado com os índios Tukano do médio rio Tiquié, na bacia Rio Negro, Amazonas (AM). A pesquisa realizada fez uso dos conceitos da Etnoastronomia e teve como suporte teórico os conhecimentos da Etnomatemática. Segundo o pesquisador seu trabalho consistiu basicamente em criar, juntamente com populações indígenas local, um calendário no qual utilizou-se os conhecimentos de ciclos naturais, constelações astronômicas e rituais presentes no cotidiano dessas etnias. O calendário tem um

\footnotetext{
9 “Os Tembé-Tenetehara (Verdadeiros homens da floresta) pertencem ao tronco Tupi, estando distribuído por diversas tribos nos Estados do Pará e Maranhão” (BARROS, 2004, p. 40).

10 “A Etnomatemática é uma proposta de Teoria Epistemológica que possui correntes diferentes. Numa delas pode ser considerada também a arte ou técnica (techné = tica) de explicar, de entender, de se desempenhar na realidade (matema), dentro de um contexto cultural próprio (etno)" (D’AMBRÓSIO, 1993, p. 9).
} 
formato circular e foi composto de uma série de círculos concêntricos que apresentam movimentos independentes. Nota-se, que nesse trabalho, a abordagem de aspectos importantes como: etnoastronômicos, socioculturais e simbólicos.

Lima (2011) faz uma análise de como a Astronomia Cultural pode ser estudada a partir de fontes etnohistóricas e se aprofunda no estudo de caso da cultura Bororo ${ }^{11}$ e de suas relações com o Céu (vide também LIMA, 2012 apud JAFELICE, 2012).

Jafelice (2011, p. 1) expõe suas leituras “[...] sobre Astronomia Cultural e Educação Intercultural e apresenta uma crítica das narrativas recorrentes na formação do astrônomo". Discute ainda sobre "[...] a deficiência na formação desses profissionais em áreas importantes do conhecimento como: história, filosofia e sociologia da ciência, e principalmente em antropologia, demonstrando preocupação quanto à qualidade e benefício do trabalho de quem pretende se envolver com Astronomia Cultural" (JAFELICE, 2011, p. 1).

A fim de reafirmar a necessidade de pesquisas em AC, Jafelice (2012) ressalta a importância na formação dos profissionais que pretendem trabalhar nessa área. O pesquisador apresenta ainda "[...] uma bibliografia básica para trabalhos em $A C$, que espera servir como uma orientação inicial para interessados nesse tipo de discussão e pesquisa” (JAFELICE, 2012, p. 3, grifos do autor).

Mello, Soares e Kerber (2012, p. 1) aprofundam a discussão sobre educação intercultural "a partir de experiências em ensino de Astronomia e ciências naturais em cursos de formação de professores indígenas". [...] "Eles refletem sobre esse ensino nos contextos de diversidade cultural e, adotando a abordagem metodológica do relativismo cultural, exemplificam a prática daquela educação através do estudo de caso da cosmologia Guarani” (MELLO; SOARES; KERBER, 2012 apud JAFELICE, 2012, p. 7).

Jafelice (2015, p. 1) discute a importância da adoção da perspectiva antropológica no trato de assuntos relacionados à Astronomia Cultural e apresenta propostas de práticas para quem quiser introduzir Astronomia Cultural na educação básica - “[...] do início do $1^{\circ}$ ano do Ensino Fundamental ao final da $3^{a}$ série do Ensino Médio, seja na educação formal ou não formal". O trabalho do pesquisador "[...] é proposto no contexto de uma educação ambiental holística e transdisciplinar" na qual a abordagem busca valorizar "o vivenciar e visa uma educação humanística, acolhedora de diversidades epistemológicas e culturais" (JAFELICE, 2015, p. 1, grifo do autor). As práticas sugeridas pelo autor “[...] também podem ser usadas com proveito para encaminhar trabalhos de inclusão de conteúdos das culturas indígenas e afrodescendentes brasileiras no currículo, conforme a nova legislação exige" (JAFELICE, 2015, p. 1).

Garcia et al. (2016) identificaram o conhecimento etnoastronômico de uma comunidade indígena do norte do Rio Grande do Sul os quais usaram como subsídio para a produção de um material paradidático utilizado na escola local. A pesquisa foi realizada em três etapas: oficina pedagógica, levantamento do conhecimento de Etnoastronomia e confecção do livreto paradidático.

\footnotetext{
${ }^{11}$ Os Bororo são uma etnia indígena brasileira do Estado do Mato Grosso. Esse também é o nome da língua falada por esse grupo indígena. Seu tronco linguístico é o Macro-Jê, autodenominada Boe.
} 
Uma proposta para a inclusão de tópicos de astronomia indígena brasileira ...

Com relação à revisão efetuada nos livros didáticos foram consultados 15 exemplares de Física, dos quais sete faziam, no momento da pesquisa, parte do Programa Nacional do Livro Didático para o Ensino Médio (PNLEM) e oito não o integravam. A escolha dos livros que pertenciam ao acervo do PNLEM foram devidos à utilização desses recursos didáticos pelos estudantes do Ensino Médio da rede de ensino público. Por outro lado, os oito livros que não eram apontados pelo PNLEM, no momento de nosso levantamento, foram escolhidos por sua popularidade entre os professores de Física e por serem utilizados com frequência na rede de ensino particular do Distrito Federal.

Analisando os livros selecionados percebeu-se que a Astronomia está presente nesses materiais de forma fragmentada tendo uma maior distribuição nos capítulos que tratam de Gravitação Universal, além, de possuírem textos complementares que estão dispersos em outros capítulos.

Identificou-se que apenas a obra de Pietrocola et al. (2011) possui uma estrutura atualizada e bem organizada de seus conteúdos e inclui no capítulo 1 do volume 1 de sua coleção a explicação que algumas Culturas Antigas deram para certos fenômenos da natureza e como a concepção sobre o Universo se transformou a partir dessas explicações até os dias atuais. De forma a complementar o capítulo há uma proposta de atividade que envolve pesquisa e posterior debate sobre a visão do Universo dos indígenas brasileiros. Porém, no restante desse volume e nos outros volumes dessa mesma coleção, nada mais consta sobre alguma temática relativa à Astronomia Cultural.

\section{Diálogo com o Ensino de Astronomia}

Fazendo uso da educação dialógica de Paulo Freire iniciou-se a aplicação da proposta por intermédio do professor pesquisador. Levou-se em consideração que a sala de aula seria um ambiente adequado para esse tipo de investigação estimulando dessa forma o diálogo e a exploração do tema central, utilizando indagações de caráter mais geral. Fizemos inicialmente alguns questionamentos, como por exemplo: a formação do Universo foi interpretada igualmente por todas as Culturas? Sobre esse tema: o que pensavam os chineses? Os egípcios antigos? Os maias? E os indígenas brasileiros? Como seria escolher a boa época de preparar as sementes para o plantio de trigo no Egito antigo? Como interpretar o sumiço da Lua no meio de uma noite de lua cheia em Atenas no século IV a.C.? O que pensavam as diversas Culturas que viveram no mesmo período? Como se explicam essas visões atualmente?

Nessa perspectiva explicou-se que as respostas para esses e para diversos fenômenos astronômicos foram sendo construídas ao longo dos séculos por várias civilizações, mas que estamos em pleno processo de transformação e, no futuro próximo, poderá surgir esclarecimentos ainda bem mais plausíveis. E que mesmo no caso de conceitos que divergem completamente entre si, existe a necessidade de entender como eles estão relacionados com seus contextos e diferentes ambientes socioculturais e conjunturais. Em outras palavras, as divergências de conceitos não se limitam ao que está certo ou errado, mas ao que satisfaz um determinado modelo explicativo ou outro, entendendo que espaços e tempos bem como interações entre grupos sociais diferentes podem representar explicações bastante completas.

Desta forma, por meio do processo dialógico e da problematização surgiu a oportunidade de estimular os estudantes ao aprendizado e a valorização de seus conhecimentos prévios. 
Buscou-se apresentar essas aulas com atividades dinâmicas e atrativas, além de fazer uso de recursos instrucionais, didáticos e computacionais (data show, aplicativos como Stellarium, etc.).

Diferentes estratégias didáticas foram utilizadas para motivar os estudantes a aprendizagem como também para atrair a curiosidade deles. Destacamos textos que abordaram em seu contexto a História da Astronomia e da AIB; aplicativos de simulações; filmes e documentários; aulas práticas com oficinas para construção de um relógio solar que, eventualmente e a seu modo pode ter sido utilizado por indígenas; além de elementos da Cultura indígena presentes no cotidiano dos estudantes. Essas estratégias foram mediadas por diálogos, sendo que grande parte delas aplicadas em sala de aula e outras exploradas fora dela, como uma atividade prática que resultou em uma noite de observação ${ }^{12}$ astronômica cuja finalidade foi identificar estrelas, constelações, etc.

Após a aplicação dessas atividades, das reflexões construídas no processo e tomando por base o pensamento freiriano, notou-se que tanto o enfoque no ensino de tópicos de AIB quanto o método de investigação temática proposto por Freire fugiu do tradicionalismo das aulas Física da escola uma vez que a seleção de conteúdos se deu a partir da identificação de temas que contemplam situações cotidianas e outros que não faziam. Além disso, percebeu-se que ambas as propostas se concentram em realizar uma contextualização dos conhecimentos provenientes da Cultura integrando-os à realidade dos estudantes.

É certo que outras atividades podem ser potencialmente aplicadas e testadas como as apresentas e sugeridas por Jafelice et al. (2010) e Jafelice (2016), como por exemplo: aulas de campo com a observação do Sol, práticas observacionais noturnas mais específicas para o grupo participante da pesquisa, montagem de um calendário, visitação de sítios arqueológicos e/ou memoriais, levantamento de relatos e registros históricos e elaboração de texto coletivo. Essas atividades e outras que vierem a surgir são formas eficazes de complementar e enriquecer aquelas que foram aplicadas durante a realização da pesquisa.

\section{Material didático}

O Caderno ${ }^{13}$ de orientações para o Professor de Física é um recurso didático que foi elaborado visando o Ensino da AIB. Ele atua como um instrumento de suporte para esse profissional, podendo também ser adaptado para o docente dos diversos segmentos de ensino. A ideia é que o material não se torne uma ferramenta tecnicista nos moldes de uma cartilha, manual, guia ou algo semelhante, mas sim como um mecanismo didático de fácil compreensão. Nele se encontra algumas práticas didáticas de apoio ao Ensino de Astronomia com o propósito de difundir e popularizar esta ciência nas escolas públicas e privadas.

\footnotetext{
${ }^{12}$ A atividade de observação do Céu foi aplicada juntamente com outro projeto da escola denominado "De olho no Céu". Porém, para participar do projeto que envolveu estudantes de todas as séries do EM a seleção deles se deu por meio de critérios lançados em edital. Portanto, para esta pesquisa, não foi possível analisar qualitativamente e quantitativamente o comportamento dos estudantes do $1^{\circ}$ ano envolvidos, pois nem todos participaram do projeto.

${ }^{13}$ Disponível em Araújo (2014).
} 
Uma proposta para a inclusão de tópicos de astronomia indígena brasileira ...

Na busca de uma melhor compreensão o Caderno foi dividido em duas partes. A primeira é dedicada a um texto reflexivo sobre AIB em um contexto geral que servirá de apoio ao docente; a segunda apresenta algumas sugestões de atividades didáticas a serem aplicadas em sala de aula ou fora dela.

\section{Procedimentos metodológicos}

A pesquisa foi realizada em uma escola particular de ensino localizada na cidade satélite de Taguatinga no Distrito Federal. Sua aplicação foi conduzida em três turmas de primeiro ano do Ensino Médio do turno matutino configurando um grupo de 64 estudantes. Optou-se por essa série por ser comum, no currículo de Física das escolas brasileiras, o estudo dos conteúdos referente à Mecânica e Gravitação Universal que permitem em seu contexto o estudo da Astronomia. Cabe ressaltar que um dos coautores deste artigo foi o próprio professor regente e que o grupo participante da pesquisa não teve influências diferenciadas, já que todos os estudantes foram submetidos às mesmas etapas da pesquisa não havendo, portanto, separação em grupo experimental e grupo controle.

A divisão da pesquisa se deu em quatro etapas: (1) enquete aplicada para os estudantes; (2) roteiro de pesquisa e aula introdutória; (3) aplicação de um pós-teste; e (4) aplicação da avaliação da metodologia.

A enquete aplicada teve como objetivo verificar se os estudantes possuíam conhecimentos básicos sobre Astronomia, além de investigar fatores como: se já estudaram Astronomia no Ensino Fundamental ou Médio; se teriam o interesse em aprender novos temas relacionados a essa Ciência; se saberiam definir o que é uma constelação; se têm o hábito de observar o Céu noturno e se já o fizeram com o auxílio de um telescópio; e se conseguiriam relacionar algumas Culturas com o estudo da Astronomia.

O desenvolvimento de parte da metodologia consistiu em uma pesquisa realizada pelos estudantes e uma aula introdutória sobre AIB. O roteiro guia de pesquisa ${ }^{14}$, primeiro momento da etapa, foi apresentado aos estudantes antes da aplicação da aula e teve como objetivo auxiliá-los na busca de informações relevantes acerca do tema. O roteiro teve o intuito de incentivá-los a pesquisarem informações que pudessem complementar e enriquecer a participação durante a aula, bem como estabelecer para o grupo um maior desempenho quanto à elaboração do trabalho acadêmico.

A aula ministrada teve o propósito de contextualizar em forma de tópicos a Astronomia de três povos indígenas brasileiros (Guarani, Tukano e Tembé-Tenetehara) os quais foram estudados pelos pesquisadores Afonso (2006, 2009, 2013), Cardoso (2007) e Barros (2004), respectivamente. A escolha dessas tribos se deu durante a análise dos artigos e trabalhos acadêmicos supracitados. Os estudantes foram instigados a participarem, contribuindo com seus conhecimentos adquiridos durante a pesquisa realizada e com suas ideias para fortalecer

\footnotetext{
${ }^{14}$ Disponível em Araújo (2014).
} 
as discussões e debates a partir de temas geradores trazidos pelo pesquisador ou pelos demais componentes do grupo.

O Caderno de orientações foi o material didático de apoio elaborado pelo professor pesquisador para a preparação da aula bem como a atividade sugerida. Durante a aplicação da metodologia realizou-se apenas uma atividade com os estudantes das cinco atividades contidas na proposição didática. Isso se deu devido à limitação de tempo das aulas durante os dois bimestres em que foi aplicada a pesquisa.

A atividade consistiu na construção de uma maquete ou uma réplica de um relógio solar cuja base de construção é uma haste vertical também chamada de gnômon. Esse modelo de relógio solar foi construído com materiais acessíveis e de baixo custo. O objetivo da atividade foi incentivar os estudantes a construírem o seu próprio observatório solar a fim de obter o horário local, bem como a localização dos pontos cardeais. Além disso, modelos similares a relógios solares ou até mesmo objetos mais simples como gnômons podem ter sido utilizados por populações indígenas para marcar a passagem do tempo. O uso de relógios solares por populações indígenas não é consensual entre os pesquisadores da Astronomia Cultural. Desse modo, nosso objetivo com essa atividade foi de mostrar aos estudantes a possibilidade de medições de tempo simples, usando recursos técnicos pouco sofisticados.

O último momento para obtenção dos dados envolveu mais duas etapas: a terceira etapa consistiu em um pós-teste que foi aplicado após a intervenção da metodologia e teve como objetivo verificar o entendimento dos estudantes sobre a AIB e sua compreensão a respeito das várias interpretações do Céu noturno na ótica de outras Culturas. Nessa etapa houve uma atividade prática em que o objetivo foi fazer com que os estudantes identificassem, por meio de uma imagem retirada do Stellarium, algumas das principais constelações ocidentais, como também, na mesma região uma constelação indígena brasileira. A quarta etapa, ou seja, a avaliação da metodologia objetivou verificar a opinião dos estudantes sobre o trabalho desenvolvido e suas sugestões de melhorias para futuras aplicações desta pesquisa.

\section{Análise e discussão dos dados}

Os dados coletados durantes as etapas da pesquisa foram analisados de forma qualitativa. Para isto, as respostas obtidas na enquete, no pós-teste e na avaliação da metodologia foram examinadas separadamente para determinar melhor visualização do objetivo proposto.

\section{Etapa 1: Enquete aplicada aos estudantes}

Com intuito de caracterizar o perfil do grupo de 64 estudantes do $1^{\circ}$ ano do Ensino Médio a respeito de seus conhecimentos prévios sobre Astronomia houve a aplicação de uma enquete contendo seis questões, sendo duas de caráter objetiva e quatro objetivas/subjetivas. Para a análise levou-se em consideração que a disciplina de Física na escola é dividida em duas frentes (Física 1 e 2), sendo que, no primeiro bimestre letivo o professor F1 (Física 1) trabalhou com os estudantes noções básicas de Astronomia. Portanto, as respostas analisadas na enquete superaram as expectativas acerca dos conhecimentos obtidos por eles devido o tema já ter sido abordado com o grupo. 
Uma proposta para a inclusão de tópicos de astronomia indígena brasileira ...

A primeira questão teve como objetivo averiguar se o grupo já tinha estudado Astronomia durante o Ensino Fundamental ou Médio. Das respostas obtidas 83\% (53) afirmaram quem sim.

A questão de número 2 buscou verificar se os estudantes teriam algum interesse em conhecer novos temas relacionados à Astronomia. Analisando as respostas 84\% (54) revelaram que sim. Não houve pretensão em saber quais temas eles já tinham estudado ou pretendiam aprender.

$\mathrm{Na}$ questão 3 as respostas obtidas apontaram que 86\% (55) do estudantes já ouviram falar em uma constelação e as mais citadas por eles foram: Cruzeiro do Sul, Escorpião e Órion. Tivemos ainda 29 citações considerando as Três Marias ${ }^{15}$ como uma constelação, fato que demonstrou um equívoco na resposta dada por eles. Não houve nenhuma citação de constelações indígena brasileira.

Cerca de $77 \%$ (50) marcaram, na questão 4, a alternativa de que têm o hábito de observar o céu noturno com certa frequência. Já na questão 5 quando questionados se já tiveram a oportunidade de ter realizado alguma observação astronômica através de um telescópio, 70\% (45) afirmaram nunca ter tido.

Por fim, a questão 6, solicitava aos estudantes que apontassem qual (ais) Cultura (as) eles conseguiriam relacionar com a Astronomia. Dentre as mais citadas aparecem: maia, grega, egípcia e romana. O Gráfico 1 mostra a quantidade de citações de Culturas assinaladas pelo grupo de estudantes.

Gráfico 1. Relação entre Culturas e Astronomia apontadas pelos estudantes - Questão 6 da enquete aplicada aos estudantes

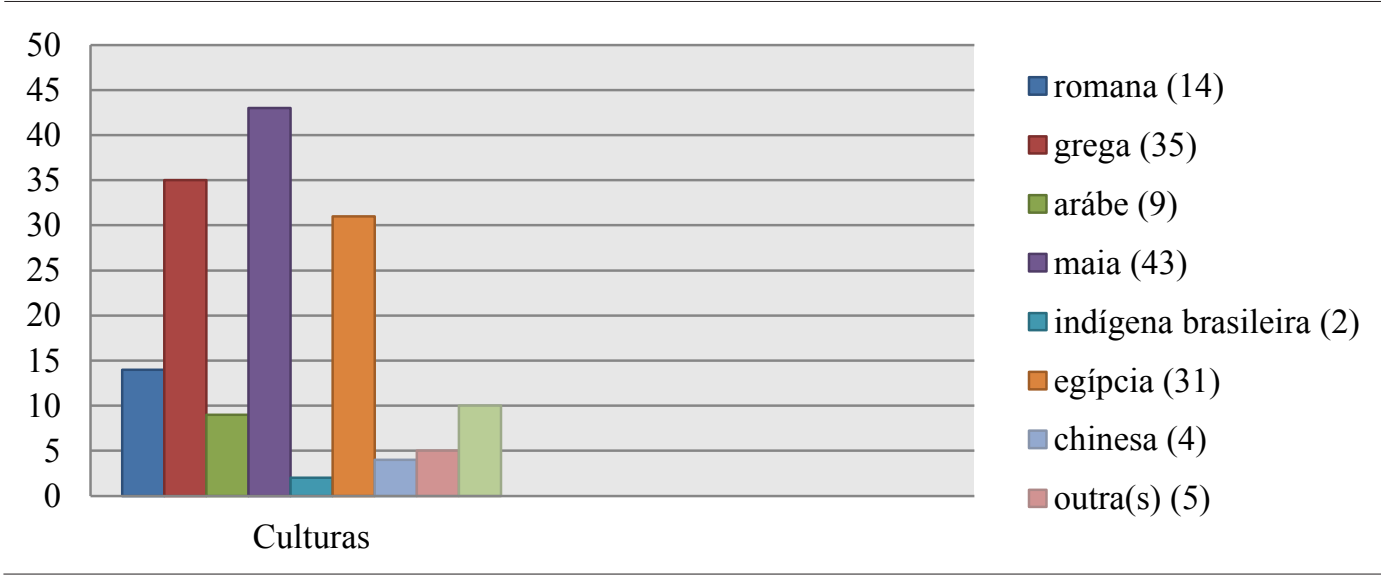

Fonte: Araújo (2014).

\footnotetext{
${ }^{15}$ Três Marias é o nome popular dado a um asterismo de três estrelas que formam o cinturão da constelação de Órion, o caçador. As estrelas são facilmente identificadas no Céu e são um importante alvo para se localizar diversas estrelas e constelações.
} 
Portanto, verifica-se no Gráfico 1 que o maior número de citações apresenta a civilização Maia como a Cultura que mais teve relação com a Astronomia. Acredita-se que esse apontamento se deu devido à popularidade que o ano de $2012^{16}$ proporcionou a essa Cultura. A grega, em segundo lugar, por ser uma das Culturas que mais influenciaram a nossa civilização e 10 estudantes não assinalaram nenhuma opção. As duas citações que relacionam a Cultura indígena brasileira à Astronomia se deu pelo fato de dois estudantes terem marcadas todas as Culturas, porém, não significa que eles possuem algum conhecimento sobre AIB.

\section{Etapa 2: Pesquisa realizada pelos estudantes e aula sobre tópicos de AIB}

O roteiro de pesquisa apresentado ao grupo de estudantes foi desenvolvido com objetivo de auxiliá-los na busca de informações que contemplassem Astronomia indígena brasileira, pois essa etapa consistia em um levantamento de dados sobre o tema, que resultou na elaboração de um trabalho escrito. O roteiro serviu também como mecanismo de contribuição para o desempenho e participação do grupo durante as aulas sobre AIB. Após a análise dos trabalhos escritos e dialogando com os estudantes notou-se que uma das dificuldades apontadas por eles durante a pesquisa foi em obter fontes bibliográficas que apresentassem o tema sugerido pelo professor pesquisador. Identificou-se que a única referência utilizada por eles teve como resultado alguns sítios da Internet, mesmo com a dificuldade em obter informações que tratassem do assunto.

Com relação à aula sobre Tópicos de AIB, utilizou-se o Caderno de Orientação para o professor de Física como elemento central, procurando-se a todo o momento fazer uso do pressuposto teórico de Paulo Freire a fim de estimular o diálogo entre professor pesquisador e os estudantes.

Por ser um tema que não fazia nenhuma relação com alguma experiência já vivenciada pelos estudantes, atribui-se nesse momento a importância da pesquisa realizada por eles sobre o tema. A aula foi predominante expositiva dialógica, na qual foi usado um computador (Notebook) e um projetor de imagens (Data Show). Para o melhor desempenho durante a exposição da aula os estudantes foram instigados por meio de questionamentos a participarem ativamente dela. Suas ideias e opiniões apresentadas foram fundamentais para motivar discussões o que tornou o assunto e a aula bem mais atrativa.

\section{Etapa 3: Análise das respostas obtidas no pós-teste}

O pós-teste ${ }^{17}$ foi constituído de sete questões sendo duas delas subjetivas e cinco objetivas. As questões envolviam situações relacionadas aos tópicos abordados de Astronomia indígena brasileira. As questões tiveram como suporte para a sua elaboração o Caderno de orientação com exceção a questão de número 7 que foi retirada do Exame Nacional do Ensino Médio (ENEM).

\footnotetext{
${ }^{16} \mathrm{O}$ término do ciclo maia (calendário maia) serviu para dar origem ao boato de que o mundo chegaria ao fim em 21/12/2012.

${ }^{17}$ Disponível em Araújo (2014).
} 
Uma proposta para a inclusão de tópicos de astronomia indígena brasileira ...

A categorização das respostas se deu da seguinte forma: Cientificamente Aceitas (CA); Aceitas em parte ou incompletas (AP/I); Não aceitas cientificamente (NAC) e; Não soube ou não respondeu $(\mathrm{N})$. Para esta pesquisa entende-se por CA aquelas respostas que tiveram relação e coerência com as concepções de Etnoastronomia. Por outro lado aquelas que não estão relacionadas a ela foram consideradas NAC. Objetivando manter preservada a identidade dos estudantes adotou-se a letra inicial da palavra estudante seguido de um respectivo número. Exemplo: E01 (Estudante 01).

É preciso considerar que dos 64 estudantes que fizeram parte da pesquisa, 58 deles responderam o pós-teste e seis não compareceram a escola no dia da aplicação. Portanto, participaram dessa etapa 58 componentes do grupo.

A questão 1 buscou identificar o que os estudantes compreenderam por AIB ou qual sentido eles atribuíam a ela. As respostas que mais apareceram como definição ou significado são: corpos celestes (Sol, Lua), constelações, relógio solar e estações do ano. Foram 25 respostas CA, representando $43,1 \%$ dos estudantes que obtiveram êxito na questão e a definiram com certa precisão. As AP/I resultaram em 21, ou seja, 36,2\% chegaram a uma definição coerente. As NAC foram 11 respostas que corresponderam a 19\%, pois não tinham nenhuma relação com o tema, e, por fim, apenas $01(1,7 \%)$ não soube ou não respondeu.

Como não há uma definição precisa para explicar o que é AIB observa-se que a maioria das respostas dadas pelos estudantes estão relacionadas às atividades cotidianas dos indígenas e que de certa forma estão diretamente ligadas as praticas astronômicas. Portanto, notou-se que houve um esforço significativo, por parte do grupo, em compreender as ideias discutidas durante a aula.

A questão de número 2 buscou verificar quais as constelações indígenas brasileiras os estudantes identificavam como as mais conhecidas, considerando os conhecimentos adquiridos por eles durante a aplicação da pesquisa. Essa questão não tinha alternativa, o que obrigava o estudante a escrever as constelações que julgasse corretas. As constelações indígenas brasileiras mais citadas foram: Ema, Homem velho, Anta e Veado. Mencionaram, também, constelações que não fazem parte do acervo indígena como: Cruzeiro do Sul, Escorpião e Órion. O Gráfico 2 apresenta o percentual de citações das constelações indígenas apresentadas pelo grupo de estudantes.

Gráfico 2. Respostas obtidas na questão 2 do pós-teste

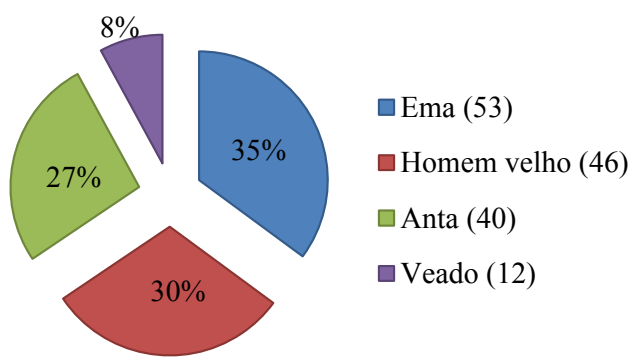

Nota-se que foram indicadas no gráfico apenas constelações dos povos Guarani, que representa apenas uma dentre várias outras Culturas indígenas brasileiras Fonte: Araújo (2014). 
A questão 3 teve o objetivo de verificar, por meio de uma simulação, como os estudantes se comportariam em uma situação prática que envolveria a observação e identificação de algumas constelações presentes no céu noturno. A situação hipotética consistiu em ensinar os estudantes a observarem o movimento aparente das estrelas em uma determinada noite do mês de setembro tendo como localização o Distrito Federal. Duas figuras (1A e 1B) retiradas do Stellarium representaram a situação descrita e foram disponibilizadas para identificação e esboço das constelações ocidentais e indígena brasileira. Para a realização da atividade foi necessário a inversão das cores das imagens. A Figura 1A apresentava as constelações do Cruzeiro do Sul e Escorpião e a Figura 1B na mesma região do Céu a constelação da Ema para o povo Guarani.

Figuras 1,1A, 1B: À esquerda: Céu noturno de Brasília no dia 05 de setembro de 2013 (Imagem extraída do Stellarium 0.12.1); No centro (1A): Esboço da localização das constelações do Escorpião e Cruzeiro do Sul no céu noturno realizado por um estudante (E50); À direita (1B): da constelação indígena da Ema no céu noturno do DF feito por um estudante (E19).
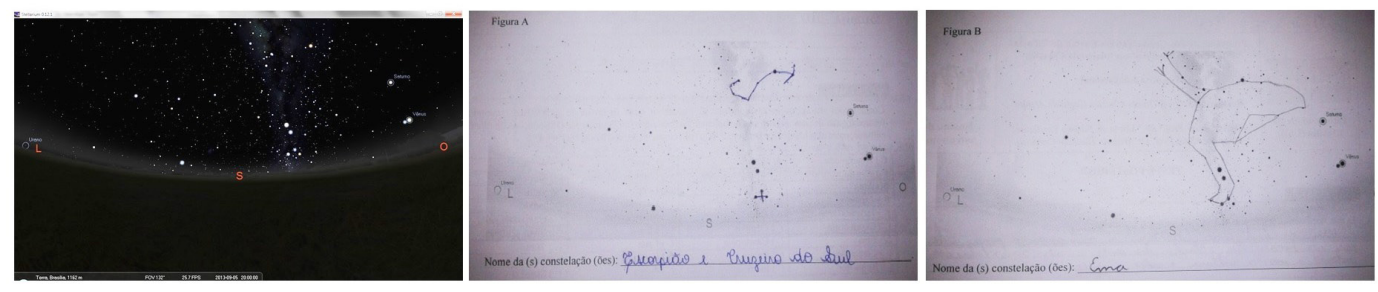

Fonte: Araújo (2014).

Analisando as respostas e os desenhos obtidos pelo grupo de estudantes na Figura $1 \mathrm{~A}$, apenas $5,2 \%$ (03) deles conseguiram identificar e fazer o esboço dos desenhos das constelações ocidentais Cruzeiro do Sul e Escorpião. Sendo que 19\% (11) conseguiram identificar a região do céu noturno, escrevendo os nomes das constelações e fazendo o desenho somente da constelação do Cruzeiro do Sul. Houve uma dificuldade de interpretação do que foi solicitado, pois 29,3\% (17) citaram unicamente o nome da constelação do Cruzeiro do Sul e 10,3\% (06) fizeram o esboço do desenho dessa constelação. Apenas 8,6\% (05) identificaram a constelação do Escorpião, porém não conseguiram reproduzir a imagem. Acredita-se que 19\% (11) não se situaram no céu noturno presente na imagem, pois identificaram constelações que não estavam visíveis na região e, 8,6\% (05) não citaram e nem esboçaram o desenho.

Com relação à atividade que foi proposta na figura 1B solicitou-se a identificação do nome e um esboço do desenho que representa a constelação indígena brasileira da Ema. Do grupo de estudantes 43,1\% (25) identificaram que naquela região do Céu estava localizada a constelação da Ema, porém não fizeram o desenho da mesma. Apenas 10,3\% (06) conseguiram identificar e desenhar corretamente a constelação, 12,1\% (07) esboçaram de forma errada e não fizeram a identificação e 20,7\% (12) não desenharam e nem identificaram. Verificou-se ainda 
Uma proposta para a inclusão de tópicos de astronomia indígena brasileira ...

que 13,8\% (08) não se situaram no céu noturno representado na figura, pois identificaram e/ ou desenharam na região a constelação Homem Velho dos Guarani.

Acredita-se que a grande dificuldade de visualizar a constelação da Ema se deu por alguns motivos, como: por ficar em uma região limitada da Via Láctea e entre as constelações ocidentais do Cruzeiro do Sul e Escorpião e outras (Mosca, Centauros, Triângulo austral, Telescópio, Lobo e Compasso), como também, por envolver a nebulosa escura Saco de Carvão ao lado da estrela de Magalhães. A área ocupada por essa constelação é bastante extensa no Céu sendo provável que a falta de prática de observação e reconhecimento do céu noturno a olho nu dificultou, por parte dos estudantes, a visualização da constelação da Ema durante a atividade prática proposta.

Na questão 4 objetivou-se verificar se os estudantes saberiam explicar como é construído o relógio solar e como se dá seu funcionamento. Das respostas obtidas, 72,4\% (42 delas) foram consideradas CA, 13,8\% (08) AP/I, 10,4\% (06) NAC e 3,4\% (02) em branco.

A questão 5 buscou averiguar se os estudantes sabiam como os índios brasileiros conseguem determinar as estações do ano e o meio dia solar fazendo uso do relógio solar. Essa atividade foi uma das etapas da pesquisa mais difíceis de serem desenvolvidas pelo grupo de estudantes, ou seja, apenas 13,8\% (08) conseguiram responder a pergunta e ainda de uma forma parcial. Eles atribuíram à identificação do meio dia solar para o Sol posicionado em cima de suas cabeças. Outros até citaram o meridiano. Os estudantes não se deram conta de que os indígenas não tinham ou não têm o mesmo registro do que vem a ser o Meridiano. Para a determinação das estações do ano atribuíram em suas respostas argumentos do tipo: "o Sol permanece por muito tempo em um determinado lugar, como também, devido à projeção de sua sombra na superfície da Terra".

A questão 6 apresentou uma relação com os nomes de algumas constelações de diversas Culturas e uma nebulosa e ao mesmo tempo solicitou aos estudantes que identificassem oito constelações indígenas brasileiras. O Gráfico 3 apresenta as oito mais assinaladas, dentre as quais inclui seis constelações indígenas brasileiras (homem velho, ema, anta, veado, canoa e queixo da anta), uma constelação ocidental (mosca) e uma nebulosa (camarão). Foram citadas por eles, também, a constelação de peixes, jararaca e cruzeiro do Sul. Por se um número pequeno de citações foi conveniente não inseri-las no gráfico.

A questão 7 foi retirada do ENEM de 2008 e faz uma abordagem sobre alguns conceitos básicos da Astronomia indígena brasileira. Vale destacar que ela não fazia parte das questões envolvendo as habilidades de Física e sim de interpretação de texto da Língua Portuguesa. A questão mostra a constelação da Ema e o mito Guarani. Para respondê-la não é necessário que os estudantes tenham domínio da AIB, pois ela traz em seu enunciado e nas ilustrações informações necessárias para que o candidato tenha êxito na resposta.

Portanto a questão apresenta quatro afirmativas para serem julgadas e cinco alternativas, sendo a opção de letra "d" a correta. O Gráfio 4 evidencia o percentual de marcação na aplicação da questão 7 , em que $52 \%$ dos estudantes acertaram a questão, o que demonstra um resultado muito representativo para a finalidade desta pesquisa.

Esta questão se torna interessante, pois se baseia na observação do Céu feita por povos distintos, com Culturas diferentes, em épocas também variadas. O resultado é muito diverso: os indígenas veem nas estrelas a figura de uma ave do ambiente no qual vivem e que fazem parte de seus mitos; os europeus enxergam símbolos mitológicos (Órion) e os cristãos (Cruzeiro). 
3. Respostas obtidas na questão 6 do pós-teste.

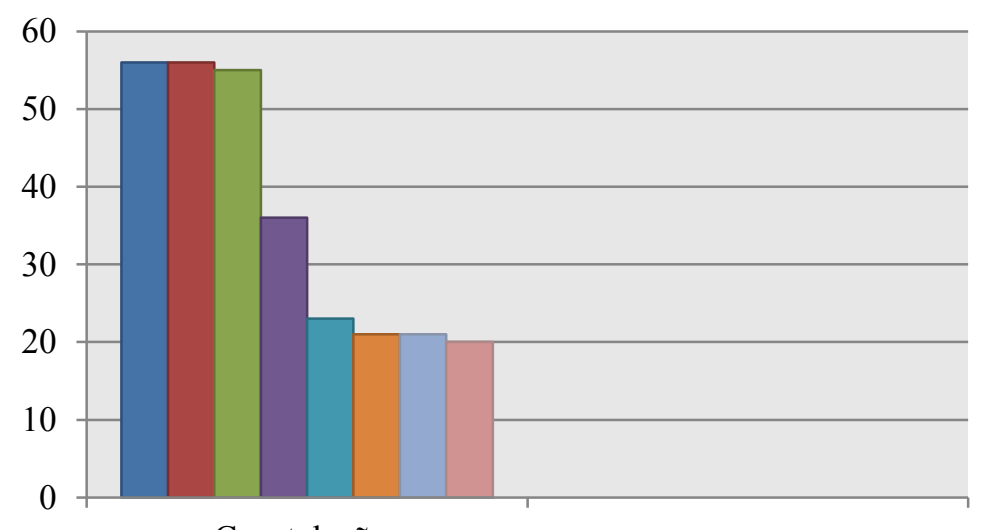

$\square$ Homem Velho (56)

口Ema (56)

$\square$ Anta (55)

$\square$ Veado (36)

Mosca (23)

$\square$ Canoa (21)

- Camarão (21)

Constelações

$\square$ Queixo da Anta (20)

Fonte: Araújo (2014).

Gráfico 4. Percentual de marcação na questão 7 do pós-teste

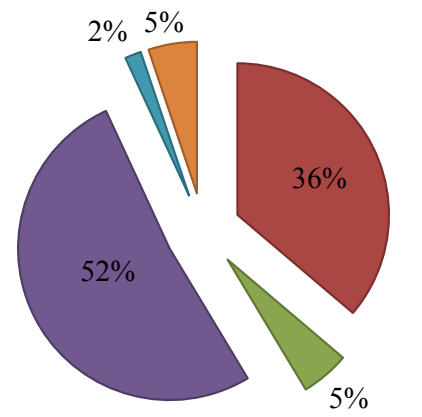

$\square$ a (zero)

$\square \mathrm{b}(21)$

$\square \mathrm{c}(03)$

$\square \mathrm{d}(30)$ - correta

$\square \mathrm{e}(01)$

$\square$ em branco (03)

Fonte: Araújo (2014).

\section{Etapa 4: Avaliação realizada pelos estudantes da metodologia aplicada}

Ao final das demais etapas foi solicitado ao grupo de estudantes que preenchessem uma Avaliação da Metodologia a fim de que apresentassem suas impressões em relação às atividades desenvolvidas durante a realização da pesquisa. As respostas demonstraram satisfação, indicando ser uma alternativa viável para as aulas de Física. Segundo os estudantes houve interesse, motivação e aprendizagem.

Quando questionados (questão 1) sobre o que acharam de ter estudado tópicos de Astronomia indígena dentro da disciplina de Física as respostas apareceram na forma de ex- 
Uma proposta para a inclusão de tópicos de astronomia indígena brasileira ...

pressões para qualificar a metodologia. Elas foram do tipo: muito bom, interessante, ótima, muito interessante, importante, legal, bom, curioso. Apenas um estudante não indicou satisfação e relatou: "No geral, creio que é muito superficial e vagamente empregado". Um segundo estudante não se manifestou, deixando a questão em branco.

Em relação ao conteúdo explorado em sala de aula, na questão 2 listaram-se nove temas para que os estudantes pudessem marcar somente aqueles em que o estudo da AIB foi útil em seu aprendizado. A opção mais escolhida foi a letra " $b$ " que trata da mitologia indígena brasileira seguida da letra "e" que aborda a construção do relógio solar.

Em se tratando do que mais agradou os estudantes durantes as aulas e/ou as atividades desenvolvidas sobre AIB (questão 3), a maioria relataram ter gostado de saber da existência de denominações para constelações indígenas brasileiras e não somente as greco-romanas como aparece na literatura. Outros aspectos também foram destacados como: conhecimentos astronômicos de outras Culturas, a mitologia indígena brasileira e a descoberta de novas constelações.

Perguntou-se aos estudantes (questão 4) o que eles não sabiam e aprenderam com a aula de AIB. As citações que mais apareceram como respostas e que já foram assinaladas na questão de número 3 foram as descobertas de novas constelações seguida da utilização do relógio solar. Os nomes das constelações indígenas também chamaram bastante atenção por se tratar da biodiversidade brasileira. Eles estavam acostumados com os nomes adotados na mitologia ocidental. Um estudante chegou a citar uma explicação da mitologia indígena a respeito de uma constelação: "Eu não sabia que a Ema era presa, por causa que eles achavam que se fosse solta beberia toda a água da Terra".

Deixou-se um espaço livre na questão 5 para que os estudantes pudessem fazer seus comentários a respeito das atividades desenvolvidas durante a pesquisa. Quase todos eles assumiram ter gostado e acharam que foi um conteúdo diferente do que eles estão habituados a estudar na disciplina de Física. Seis deles preferiram não se manifestar.

Os resultados obtidos por meio da avaliação da metodologia, bem como o posicionamento dos estudantes, vão ao encontro do objetivo da pesquisa, pois durante as atividades percebeu-se que a maior parte deles estava motivada em aprender sobre a AIB. Uma das justificativas dessa motivação se deu pelo fato de estarem saindo um pouco da formulação matemática que a disciplina de Física dispõe quando oferece a definição de alguns conceitos físicos.

É certo que o ensino da AIB se tornou algo novo e desafiador para o professor pesquisador como para a disciplina ofertada na escola. Por se tratar de Astronomia, os estudantes se sentem bem mais motivados para aprender algo dito novo.

Como não foi objetivo da pesquisa analisar a aprendizagem do grupo de estudantes, notou-se por meio de seus depoimentos que houve um interesse significativo em adquirir novos conhecimentos sobre a Astronomia, em especial, a praticada pelos povos indígenas brasileiros.

\section{Considerações finais}

A proposta de inserir tópicos de Astronomia indígena brasileira nas aulas de Física não teve a intenção de produzir mudanças na sequência dos conteúdos programáticos dessa disciplina, que são abordados no Ensino Médio, mas em contribuir com a divulgação do Ensino de Astronomia em um ambiente formal de ensino, assim como, proporcionar a prática de 
exercícios de aprendizagem com os estudantes utilizando um novo tema no currículo escolar e ao mesmo tempo colaborar com o ensino da cultura brasileira.

Mediante as aulas teóricas, práticas e fazendo uso do material didático elaborado durante a pesquisa confirmou-se o quanto é possível ensinar a Astronomia de uma cultura que não está relacionada com as que tradicionalmente são abordadas nas aulas de Física ou apresentadas nos livros didáticos dessa disciplina.

Verificou-se, também, que os estudantes são bastante receptivos a novas metodologias, principalmente com a abordagem de temas novos e motivadores que fazem uso de vídeo(s) e/ ou aplicativos (Stellarium, Celestia, etc.) além de várias outras atividades práticas propostas, como a construção de um relógio solar ou até mesmo a elaboração de murais.

Em relação ao material didático proposto - Caderno de Orientação para o professor de Física - foi sem dúvidas um instrumento importante para o desenvolvimento e aplicação da metodologia utilizada, ou seja, serviu como um elemento mediador que traz em sua estrutura a concepção pedagógica norteadora no processo de ensino e aprendizagem da AIB.

Por meio dessa experiência didática percebeu-se que cada vez mais é necessário investir e incentivar o Ensino da Astronomia na Educação Básica. Esse incentivo possibilitará maior abertura para aplicar, por exemplo, o ensino de AIB nas aulas de Física ou Ciências. No entanto, é preciso admitir a importância da ampliação dos objetivos educacionais propostos na pesquisa, no sentido de que haja uma aprendizagem mais significativa.

Apesar dos propósitos e capacidades educativas por temas relacionados à Astronomia Cultural terem muito a oferecer como é o caso da AIB, vale ressaltar, que as pesquisas na área de ensino de Ciências ou Física sobre tal assunto ainda são escassos. Contudo, após a aplicação da pesquisa os resultados obtidos apontaram algumas das potencialidades relacionadas ao uso do tema Astronomia indígena brasileira nas aulas de Física.

\section{Agradecimentos}

Agradecemos à escola por gentilmente ter aberto as portas sem nenhuma burocracia, aos estudantes que participaram da pesquisa e a todos que, direta ou indiretamente, nos auxiliaram na condução deste estudo. Ao Programa de Pós-Graduação em Ensino de Ciências (PPGEC) da Universidade de Brasília (UnB) pela oportunidade e aprendizado, pois sem sua existência este trabalho não teria sido concretizado. Como também a revista e seus árbitros por suas valiosas e enriquecedoras sugestões para melhoria do artigo.

\section{Referências}

AFONSO, G. B. Astronomia indígena. In: REUNIÃO ANUAL DA SBPC, 61., 2009, Manaus. Anais... Manaus: SBPC, 2009. Disponível em: <http://www.sbpcnet.org.br/ livro/61 ra/conferencias/CO_GermanoAfonso.pdf>. Acesso em: 25 abr. 2013.

. As constelações indígenas brasileiras. Disponível em: $<$ http://www. telescopiosnaescola.pro.br/indigenas.pdf>. Acesso em: 31 mar. 2013. 
Uma proposta para a inclusão de tópicos de astronomia indígena brasileira ...

AFONSO, G. B. Mitos e estações no céu Tupi-Guarani. Scientific American Brasil, São Paulo, n. 14, p. 46-55, 2006. (Edição especial).

ARAÚJO, D. C. C. Uma proposta para a inserção de tópicos de astronomia indígena brasileira no ensino médio: desafios e possibilidades. 2014. 185 f. Dissertação (Mestrado Profissional em Ensino de Ciências) - Universidade de Brasília, Brasília, 2014.

BARROS, O. S. Etnoastronomia Tembé-Tenetehara como matriz de abordagem (etno) matemática no ensino fundamental. 2004. 111 f. Dissertação (Mestrado em Educação em Ciências e Matemáticas) - Universidade Federal do Pará, Belém, 2004.

CARDOSO, W. T. O céu dos tukanos na escola Yupuri: construindo um calendário dinâmico. 2007. 390 f. Tese (Doutorado em Educação Matemática) - Pontifícia Universidade Católica de São Paulo, São Paulo, 2007.

CARVALHO FILHO, J. C.; GERMANO, A. S. M. Astronomia: contemplando o céu. Natal: EDUFRN, 2007.

D’AMBRÓSIO, U. Etnomatemática: um programa. A Educação Matemática, Blumenau, v. 1, n. 1, p 5-11, 1993.

FARES, E. et al. O universo das sociedades numa perspectiva relativa: exercícios da etnoastronomia. Revista Latino-Americana de Educação em Astronomia, São Carlos, n. 1, p. 77-85, 2004.

FAULHABER, P. “As estrelas eram terrenas”: antropologia do clima, da iconografia e das constelações Ticuna. Revista de Antropologia, São Paulo, v. 47, n. 2, p. 379-426, 2004.

GARCIA, C. S. et al. "As coisas do céu”: etnoastronomia de uma comunidade indígena como subsídio para a proposta de um material paradidático. Revista Latino-Americana de Educação em Astronomia, São Carlos, n. 21, p. 7-30, 2016.

INSTITUTO SOCIOAMBIENTAL. Povos indígenas no Brasil: Ticuna. [S.l.]: ISA, 2008. Disponível em: < https://pib.socioambiental.org/pt/povo/ticuna>. Acesso em: 24 out. 2017.

JAFELICE, L. C. et al. (Org.). Astronomia, educação e cultura: abordagens transdisciplinares para vários níveis de ensino. Natal: EDUFRN, 2010.

JAFELICE, L. C. Astronomia cultural e educação intercultural. In: SIMPÓSIO NACIONAL DE EDUCAÇÃO EM ASTRONOMIA, 1., 2011, Rio de Janeiro. Atas... Rio de Janeiro: UNIRIO, 2011. Disponível em:. Disponível em: <http://eacultural.fcaglp.unlp.edu.ar/base/ LuizCJ/Astronomia-Cultural-e.pdf > . Acesso em: 24 out. 2017.

Encontro de pesquisa: a astronomia cultural. In: SIMPÓSIO NACIONAL DE

EDUCAÇÃO EM ASTRONOMIA, 2., 2012, São Paulo. Atas... São Paulo: USP, 2012.

Disponível em: < https://www.sab-astro.org.br/wp-content/uploads/2017/03/SNEA2012_ EP_A_Astronomia-Cultural.pdf $>$. Acesso em: 24 out. 2017.

Astronomia cultural nos ensinos fundamental e médio. Revista Latino-

Americana de Educação em Astronomia, São Carlos, n. 19, p. 57-92, 2015. 
JAFELICE, L. C. O ensino de astronomia cultural: por quem, para quem, como e para quê? In: FAULHABER, P.; BORGES, L. C. (Org.). Perspectivas etnográficas e históricas sobre as astronomias. Rio de Janeiro: MAST, 2016. p. 249-267. Disponível em: <http:// www.mast.br/pdf/perspectivas_etnograficas_2016.pdf>. Acesso em: 02 dez. 2016.

LIMA, F. P. Observações e descrições astronômicas de indígenas brasileiros: a visão dos missionários, colonizadores, viajantes e naturalistas. 2004. Dissertação (Mestrado em Ciências) - Universidade Federal do Rio de Janeiro, Rio de Janeiro, 2004a.

Observações e descrições astronômicas de indígenas brasileiros: a visão dos missionários, colonizadores, viajantes e naturalistas: resumo. Revista da Sociedade Brasileira de História da Ciência, Rio de Janeiro, v. 2, n. 2, p. 175-177, jul./dez. 2004b.

- Astronomia cultural nas fontes etno-históricas: a astronomia do bororo. In: SIMPÓSIO NACIONAL DE EDUCAÇÃO EM ASTRONOMIA, 1., 2011, Rio de Janeiro. Anais... Rio de Janeiro: UNIRIO, 2011. Disponível em: < http://www.sab-astro.org.br/ Resources/Documents/snea1/mesas/SNEA2011_M3_Lima.pdf>. Acesso em: 20 dez. 2016.

LIMA, F. P.; MOREIRA, I. C. Tradições astronômicas tupinambás na visão de Claude D’Abbeville. Revista da Sociedade Brasileira de História da Ciência, Rio de Janeiro, v. 3, n. 1, p. 4-19, jan./jun. 2005.

LIMA, F. P. et al. Astronomia indígena: relações céu-terra entre os indígenas no Brasil: distintos céus, diferentes olhares. In: MATSUURA, O. T. (Org.). História da astronomia no Brasil (2013). Recife: CEPE, 2014. v. 1, p. 87-131. Disponível em: < http:/ / site.mast.br/ HAB2013/historia_astronomia_1.pdf>. Acesso em: 02 dez. 2016.

LINHARES, F. R. C.; NASCIMENTO, S. S. Espaço de divulgação de astronomia no Brasil: um mapeamento através da internet. In: ENCONTRO NACIONAL DE PESQUISAS EM ENSINO DE CIÊNCIAS, 7., 7., 2009, Florianópolis. Anais... Florianópolis: ABRAPEC, 2009.

MELLO, F. C.; SOARES, J. B.; KERBER, L. O. Astronomia e educação intercultural: experiências no ensino de astronomia e ciências em escolas indígenas. In: SIMPÓSIO NACIONAL DE EDUCAÇÃO EM ASTRONOMIA, 1., 2011, Rio de Janeiro. Atas... São Paulo: IFUSP, 2012.

MOURÃO, R. R. F. Dicionário enciclopédico de astronomia e astronáutica. Rio de Janeiro: Nova Fronteira, 1987.

PIETROCOLA, M. et al. Física em contexto: movimento, força, astronomia. São Paulo: FTD, 2011. v. 1.

Artigo recebido em 30/10/2016. Aceito em 18/04/2017.

Endereço para contato: UnB, Instituto de Química, PPGEC, Secretaria de Pós-Graduação, sala A1, 93/20, Campus Darcy Ribeiro, Asa Norte, CEP 70919-970, Brasília, DF, Brasil. 